\title{
Estimates and predictors of health care costs of esophageal adenocarcinoma: a population-based cohort study
}

\author{
Hla-Hla Thein ${ }^{1,2^{*}}$ (D), Nathaniel Jembere', Kednapa Thavorn ${ }^{3,4,5}$, Kelvin K. W. Chan ${ }^{6,7,8}$, Peter C. Coyte ${ }^{9}$,
} Claire de Oliveira $2,8,9,10$, Chin Hur ${ }^{11,12}$ and Craig C. Earle $2,6,7,8,13$

\begin{abstract}
Background: Esophageal adenocarcinoma (EAC) incidence is increasing rapidly. Esophageal cancer has the second lowest 5-year survival rate of people diagnosed with cancer in Canada. Given the poor survival and the potential for further increases in incidence, phase-specific cost estimates constitute an important input for economic evaluation of prevention, screening, and treatment interventions. The study aims to estimate phase-specific net direct medical costs of care attributable to EAC, costs stratified by cancer stage and treatment, and predictors of total net costs of care for EAC.

Methods: A population-based retrospective cohort study was conducted using Ontario Cancer Registry-linked administrative health data from 2003 to 2011. The mean net costs of EAC care per 30 patient-days (2016 CAD) were estimated from the payer perspective using phase of care approach and generalized estimating equations. Predictors of net cost by phase of care were based on a generalized estimating equations model with a logarithmic link and gamma distribution adjusting for sociodemographic and clinical factors.

Results: The mean net costs of EAC care per 30 patient-days were $\$ 1016(95 \% \mathrm{Cl}, \$ 955-\$ 1078)$ in the initial phase, \$669 (95\% Cl, \$594-\$743) in the continuing care phase, and \$8678 (95\% Cl, \$8217-\$9139) in the terminal phase. Overall, stage IV at diagnosis and surgery plus radiotherapy for EAC incurred the highest cost, particularly in the terminal phase. Strong predictors of higher net costs were receipt of chemotherapy plus radiotherapy, surgery plus chemotherapy, radiotherapy alone, surgery alone, and chemotherapy alone in the initial and continuing care phases, stage III-IV disease and patients diagnosed with EAC later in a calendar year (2007-2011) in the initial and terminal phases, comorbidity in the continuing care phase, and older age at diagnosis (70-74 years), and geographic region in the terminal phase.

Conclusions: Costs of care vary by phase of care, stage at diagnosis, and type of treatment for EAC. These cost estimates provide information to guide future resource allocation decisions, and clinical and policy interventions to reduce the burden of EAC.
\end{abstract}

Keywords: Costs and cost analysis, Esophageal adenocarcinoma, Health care costs, Stage at diagnosis, Treatment

\footnotetext{
* Correspondence: rosie.thein@utoronto.ca

${ }^{1}$ Dalla Lana School of Public Health, University of Toronto, Toronto, ON,

Canada

${ }^{2}$ Institute for Clinical Evaluative Sciences, Toronto, ON, Canada

Full list of author information is available at the end of the article
}

(c) The Author(s). 2018 Open Access This article is distributed under the terms of the Creative Commons Attribution 4.0 International License (http://creativecommons.org/licenses/by/4.0/), which permits unrestricted use, distribution, and reproduction in any medium, provided you give appropriate credit to the original author(s) and the source, provide a link to the Creative Commons license, and indicate if changes were made. The Creative Commons Public Domain Dedication waiver (http://creativecommons.org/publicdomain/zero/1.0/) applies to the data made available in this article, unless otherwise stated. 


\section{Background}

Esophageal cancer is the eighth most common cancer worldwide [1]. The incidence of esophageal adenocarcinoma (EAC) has increased rapidly in North America and other Western countries over the past several decades [2-6]. In fact, EAC has become the predominant histological subtype of esophageal cancer (relative to squamous cell carcinoma) in North America and Europe, and the sixth leading cause of cancer-related deaths worldwide $[1,7,8]$. In Canada, the incidence of EAC has risen steadily at $4 \%$ per year over the past 30 years (between 1981 and 2009), making it the most common type of esophageal cancer in Ontario [9]. These trends may be attributed to a growing and aging population, and the rise in the prevalence of important risk factors, such as obesity and gastroesophageal reflux disease (GERD) which leads to the development of Barrett's esophagus [7, 9-11]. Esophageal cancers symptomatically present late and carry poor prognoses, despite advances in multimodality treatment $[12,13]$. Esophageal cancer has the second lowest 5-year relative survival rate for people diagnosed with cancer in Canada (i.e., pancreatic cancer 9.5\%, esophageal cancer $15.3 \%$, lung cancer $20 \%$, and liver cancer 20.4\%) [14]. Therefore, diagnosing esophageal cancers at an early stage before the development of symptoms, is critical for improving prognosis [15].

Recent cancer-related cost estimates placed esophageal cancer patients who survived for more than 1 year post-diagnosis at the top of the cost table at $\$ 50,620$ (95\% CI \$47,677-\$53,562, 2009 Canadian dollars) [16]. These patients also had the highest cost for hospital admissions of all cancers $(\$ 27,506)$ due to the performance of resource intensive procedures, such as post-surgery esophageal dilation and biopsies to the esophagus or other parts of the gastrointestinal tract (through endoscopies) [16]. Additionally, these patients had frequent post-treatment follow-up visits [17], demonstrated by high costs for physician services (\$4757) and home care (\$4058) [16]. The costs were higher in the initial and terminal phases, and lower in the pre-diagnosis and continuing phases [18]. However, these studies provide estimates for EAC care that are broad in categorization, and more detailed estimates by specific clinical care elements and characteristic could provide significant data to guide clinical care, policy and future research.

Techniques to reduce EAC incidence, such as endoscopic mucosal resection or radiofrequency ablation of Barrett's esophagus, will likely be more cost-effective than current surveillance strategies that rely on early detection of cancer $[19,20]$. There is, however, limited relevant evidence in the Canadian context; costs estimates of EAC are needed for use in cost-effectiveness analyses of innovative technologies to inform health care professionals, policy makers, and the public in order to aid prevention and the early detection of EAC.

The purpose of this study was to estimate: i) the phase-specific net direct medical costs of care attributable to EAC for all adults aged 18 years and older, from the perspective of the Ontario Ministry of Health and Long-Term Care; ii) total net health care costs by cancer stage and type of treatment for EAC; and iii) predictors of the total net costs of care for individuals diagnosed with EAC.

\section{Methods}

\section{Study design and setting}

We conducted a population-based retrospective cohort study by linking the Ontario Cancer Registry (OCR) with administrative health data and a reference Ontario population to estimate the phase-specific net costs of care for primary EAC from January 1, 2003, through December 31,2011 . Individuals were followed from the day of diagnosis until death or until 12 months after the end of the study period, i.e., December 31, 2012, whichever came first. We approached costing [21-25] based on three care phases: 1) initial phase, the first 12 months after diagnosis of EAC, which would include diagnostic services, primary therapy, and adjuvant therapy to lower the risk of cancer recurrence; 2) continuing care phase, all months between the initial and terminal phases of care, which would include surveillance activities for detecting recurrences, follow-up treatment to prevent cancer recurrence, and treatment of complications following the initial therapy; and 3) the terminal phase, the final 12 months before death, which applies to care received at the end of life, often palliative in nature. For patients who died within 12 months post-diagnosis, the costs were attributed to the terminal phase only. For patients surviving $<24$ months after diagnosis, the final 12 months of observation and costs of care were allocated to the terminal phase first while the remaining months were allocated to the initial phase [21, 25]. For patients who did not die during the study period, the first 12 months (and costs) were allocated to the initial phase and all remaining months were allocated to continuing care phase [22]. We estimated phase-specific net costs of care as the difference between the mean costs for EAC cases and for matched controls without cancer [22, 24, 25]. Additionally, we stratified total net costs by stage at diagnosis and treatment for EAC, and identified predictors of total net costs.

\section{Data sources}

We conducted our analyses using population-level administrative health databases with information on all 14 million Ontario residents. Data were provided by the Institute for Clinical Evaluative Sciences, the main data 
repository for health records in the province of Ontario, Canada. These data have been validated for completeness and accuracy [26-31]. This included cancer registry linked to demographic and geographic information, physician billings for outpatient, inpatient, community-based, and laboratory services, hospital and emergency department discharge abstracts, hospital-based ambulatory care data, and prescription drugs (for those over age 65), home care, continuing care, and long-term care [32, 33].

All cancer incidence in Ontario and subsequent mortality has been captured by the OCR from 1964 onwards. The Registered Persons Database contains demographic and geographic information for all people registered for provincial government-sponsored health insurance coverage. The Ontario Health Insurance Plan (OHIP) claims database contains the records of all physician billings for outpatient, inpatient, community-based, and laboratory services starting from July 1991. Non-physician procedures with an OHIP billing number (for example, midwife, chiropractor, nurse practitioner, or physiotherapist) are also included. Billings are based on the Ontario Health Insurance Plan fee-for-service rates in effect in the year the services were provided. The Canadian Institute for Health Information Discharge Abstract Database (CIHI-DAD) contains demographic, clinical, and administrative information on inpatient hospitalizations from April 1988 onwards; and CIHI-National Ambulatory Care Reporting System (CIHI-NACRS) contains administrative, demographic, clinical, and financial data for hospital-based and community-based ambulatory care (day surgery, emergency department visits, outpatient and community-based clinics) which is available from April 2003 onwards. OHIP, CIHI-DAD, and CIHI-NACRS fee codes were used to identify surgical resection, chemotherapy and radiotherapy, as well as esophageal dilation, drainage, esophageal stenting, laser debulking of tumor, and palliative care for EAC (see Additional file 1: Table S1). We used previously published and validated fee codes for these procedures [34].

Direct medical costs were determined using the perspective of the public payer. The costing methods followed the guidelines of the Canadian Agency for Drugs and Technology in Health [33] and the Health System Performance Research Network [32], and were based on previous cancer costing work done in Ontario $[16,18,35]$. Costs associated with physician services, including outpatient visits, laboratory services, diagnostic tests, emergency physicians, and medical and radiation oncologists, were determined through the OHIP claims database. The cost of inpatient hospitalization was determined from the CIHI-DAD database. Costs associated surgical resection, chemotherapy and radiotherapy for EAC were determined using the CIHI and OHIP databases with application of standard provincial unit costs.
Emergency department visit and same-day surgery costs came from the CIHI-NACRS database. Ontario Drug Benefit Program database contains the cost of prescription medication dispensed to individuals 65 years of age and older, resident of a long-term care facility or a home for special care, recipient of services under the Home Care Program, recipient of social assistance (Ontario Works, Ontario Disability Support Program), registered under the Trillium Drug Program, or registered under the Special Drugs Program. The Ontario Home Care Services, Continuing Care Reporting System, and OHIP/ Ontario Drug Benefit Program databases were used to identify costs associated with home care, continuing care (chronic care), and long-term care.

\section{Study variables}

Variables considered in the analyses included sociodemographic characteristics: age group at diagnosis $(<50$, $50-54,55-59,60-64,65-69,70-74,75-79,80-84, \geq$ 85 years); gender (male, female); residence (rural, urban); birth country (outside of Canada, Canada); area-level income quintile (Q1-lowest; Q5-highest); Ontario administrative health region (Erie St. Clair, South West, Waterloo Wellington, Hamilton Niagara Haldimand Brant, Central West, Mississauga Halton, Toronto Central, Central, Central East, South East, Champlain, North Simcoe Muskoka, North East, North West); and clinical characteristics such as comorbidity, measured by the Johns Hopkins Aggregated Diagnosis Groups (number of ADGs: $0,1-3,4-7,8-10,11+$ ); stage at EAC diagnosis (Stage 0-earliest stage of EAC, also called high-grade dysplasia, where cancer cells are found only in the epithelium, Stage I, Stage II, Stage III, Stage IV); treatment for EAC (categorized exclusively as surgery, chemotherapy or radiotherapy alone, surgery plus chemotherapy, surgery plus radiotherapy, chemotherapy plus radiotherapy, surgery plus chemotherapy plus radiotherapy, and no treatment); year of EAC diagnosis (2003-2011); and date of death. The OCR has used the American Joint Committee on Cancer TNM staging [36] from 2003 onwards.

Individual-level income quintile was not available; therefore, area-level income quintile was used as a surrogate. Area-level income quintile was quantified using median neighbourhood household income, which was determined through linking of postal codes to Canadian census data and categorized into quintiles corresponding to income status of neighbourhoods. The income quintile 1 represents the lowest $20 \%$ of neighbourhoods and income quintile 5 represents the most well-off $20 \%$ of neighbourhoods.

Ontario has 14 health regions, called Local Health Integration Networks (LHIN) [37] which we used as a factor to explain regional health care service and 
availability. The Johns Hopkins Adjusted Clinical Groups case-mix system [38-41] was used for comorbidity adjustment [42-44].

\section{Estimates of the net cost of care for EAC patients: Matching cases and controls}

The net cost method matches cases and controls on socio-demographic and clinical factors associated with resource use and calculates the difference in cost for cancer patients and non-cancer control subjects [22, 24, 25]. Cases (cancer patients) were identified as all eligible individuals 18 years of age and older in the OCR with an International Statistical Classification of Disease and Related Health Problems (ICD-9) site codes 150.0-150.9 and ICD-10 codes (C15.3-C15.9), in combination with histology International Classification of Diseases for Oncology, Third Edition (ICD-O-3) codes 8140-8575 corresponding to primary cancer (see Additional file 1: Table S2) [45]. Individuals were excluded if the EAC diagnosis was recorded on or after the date of death or individuals whose EAC was not the primary site.

Potential controls were selected from a 5\% random sample of the reference Ontario population Registered Persons Database, including all individuals 18 years of age and older with no cancer diagnosis before or during our analysis period. Control subjects who died before the patient's EAC diagnosis date were excluded.

Two sets of cases and controls were used to match 1:1 at two index dates (date of diagnosis and 12 months preceding the date of death) to estimate costs for the initial and continuing care phases. For the latter index date, cases who died were matched 1:1 to controls with similar conditional probability of a diagnosis of EAC given the observed individual covariates [46, 47] who died on the same date to estimate costs for the terminal phase. This was derived by fitting a logistic model with EAC status as the dependent variable and the index year (year of EAC diagnosis), age group at index date, gender, urban or rural residence, neighbourhood income quintile, Ontario health region, and comorbidity [18, 35]. For each case, the closest non-EAC control was selected that matched the following criteria: age \pm 5 years at the index date; same gender; same index year; comorbidity (ADGs), and a propensity score within a caliper width of 0.2 standard deviation [48].

\section{Estimation of health care costs}

Cost estimates for inpatient hospitalizations, same-day surgery, and emergency department visits were obtained by multiplying the resource intensity weight (measure of resource utilization intensity) by the cost per weighted case (unit cost) [32, 49-51]. Costs for services included in Ontario Health Insurance Plan, Ontario Drug Benefit, and Home Care were obtained by multiplying the number of services by unit cost. Continuing care cost was determined using Continuing Care Reporting System, which contains clinical and demographic information on individuals receiving facility based continuing care. Services include medical long-term care, rehabilitation, geriatric assessment, respite care, palliative care, and nursing home care. Patients are classified into 44 Resource Utilization Groups, and are assigned a Case Mix Index that approximates their per day resource usage. Case Mix Index is reviewed every quarter and can be adjusted multiple times [32]. Continuing care cost per weighted day was derived by dividing the total annual cost by the total annual weighted day. The case cost is the product of weighted days multiplied by the cost per weighted day. The cost of long-term care was obtained through the product of the year-specific length of stay and the Ministry of Health cost per diem. All costs were adjusted to 2016 Canadian dollars using the Consumer Price Index for Health and Personal Care [52]. Costs were undiscounted (i.e., exact costs billed).

\section{Statistical analysis}

Sociodemographic and clinical characteristics and health care costs for the EAC cases and non-EAC control cohorts were summarized by phase of care. We presented categorical variables as frequencies and percentages, and continuous variables as means \pm standard deviations. For each phase of care, we estimated mean (95\% confidence interval $[\mathrm{CI}]$ ) net costs of care due to EAC (per 30 patient-days) using generalized estimating equations to account for the matched study design. Estimates were bootstrapped 1000 times to obtain CIs. Total net health care costs and by phase of care were analyzed by stage at EAC diagnosis and type of treatment received.

Generalized estimation equation model with a logarithmic link and gamma distribution, which specifies the conditional mean function directly, was used to examine unadjusted and adjusted relationships between covariates and total net health care costs per 30 patient-days by phase of care among all EAC cases [53-55]. Potential covariates included age at EAC diagnosis, gender, urban or rural residence, birth country, income quintile, Ontario health region, comorbid conditions (ADGs), stage of disease at diagnosis, treatment for EAC, and year of EAC diagnosis. Variables with a significance level of $P \leq 0.2$ in the univariate analyses were entered into the multivariate generalized estimation regression analysis and were considered independently significant when $P \leq 0.05$ [56, 57]. Interactions were considered in the context of regression analysis. The adjusted model was constructed according to a stepwise backward selection methodology and only included those variables that remained significant at the two-sided level of $P \leq 0.05$ [57]. Finally, variables that were non-significant in the 
univariate test were added to see if they became significant when adjusted for other factors [58]. Statistical analyses were conducted using SAS version 9.4 (SAS Institute Inc., Cary, NC, USA).

\section{Sensitivity analysis}

A sensitivity analysis was performed where the initial phase was defined as the first 6 months after diagnosis of EAC, the terminal phase was defined as the final 6 months before death, and the continuing care phase was defined as all months between the initial and terminal phases of care.

\section{Results}

\section{Characteristics of the study population}

A flow chart of the study population is shown in Additional file 2: Figure S1. Overall, 3035 EAC cases and 560,997 control subjects were identified during the study period 2003-2011 (see Additional file 3: Table S3). Over the period, the number of new EAC cases increased from 285 in 2003 to 413 in 2011, and the proportion of those with age group at diagnosis of 50-54, 55-59, 6064, 65-69, and 70-74 years increased from 5.8, 10.5, 8.3, 8.0, and $10.3 \%$ to $12.6,17.1,13.9,18.3$, and $12.5 \%$, respectively. Stage at EAC diagnosis was available from 2003 in the data; $126(4.2 \%)$ people were diagnosed with stage 0-I, while 420 (13.8\%) were stage II, 455 (15.0\%) were stage III, 940 (31.0\%) were stage IV, and 1094 (36.1\%) were unknown stage. In addition, the proportion of patients with known stages increased from 2003 to 2011; stage 0-I from 1.6 to $21.4 \%$; stage II from 3.1 to 12.6\%; stage III from 0.9 to $16.0 \%$; and stage IV from 2.5 to $11.5 \%$. Patients receiving treatment with radiotherapy alone after EAC diagnosis increased from 5.2\% in 2003 to $19.3 \%$ in 2011 . In addition, those not receiving treatment increased from 8.9 to $14.0 \%$. In contrast, the proportion of patients receiving surgery plus chemotherapy decreased over time, from 13.6 to $5.1 \%$. In our cohort, 2490 of EAC patients died during the mean 510 days or median 288 days of follow-up and 18,536 of controls died during the mean 2309 days or median 2373 days of follow-up.

Table 1 describes the baseline characteristics of the matched cases and controls by phase of care. Cases that contributed person-time to the initial (259 days) and the terminal phase ( 242 days) were closely matched to the controls (initial phase: 360 days and terminal phase: 360 days); however, many cases that contributed person-time to the continuing care phase could not be matched with suitable controls (726 versus 1521 days).

\section{Phase-specific health care costs and net costs of care}

The average total health care costs per 30 patient-days among EAC patients was relatively high in the initial phase (\$1139; 95\% CI, \$1079-\$1199), declined during the continuing care phase $(\$ 923 ; 95 \% \mathrm{CI}, \$ 852-\$ 995)$, and increased markedly in the terminal phase (\$9004; 95\% CI, \$8545-\$9462) (Table 2).

Estimates of the average total net costs of EAC care per 30 patient-days were highest in the terminal phase ( $\$ 8678,96 \%$ of overall EAC net costs), followed by the initial phase $(\$ 1016,11 \%)$ and continuing care phase $(\$ 669,7 \%)$ of overall EAC net costs (Table 3 and see Additional file 4: Figure S2a-S2d). The net costs of inpatient hospitalization $(85-97 \%$ of the mean health care costs of inpatient hospitalization in Table 2) and outpatient visits $(75-97 \%$ of the mean health care of outpatient visits in Table 2) due to EAC accounted for the highest cost categories across all three phases. We reported bootstrap mean and 95\% CIs derived from the generalized estimating equations on Additional file 5: Table S4. With large sample sizes, the bootstrap samples results are similar to the original sample.

\section{Total net costs of care by stage at diagnosis and treatment for EAC}

Stage IV at EAC diagnosis accounted the highest total net costs per 30 patient-days and approximately $10 \%$ of the total costs in the initial phase $(\$ 1010 ; 95 \% \mathrm{CI}$, $\$ 887-\$ 1134), 6 \%$ in the continuing care phase (\$620; $95 \% \mathrm{CI}, \$ 461-\$ 780)$, and $100 \%$ in the terminal phase $(\$ 10,000 ; 95 \% \mathrm{CI}, \$ 9106-\$ 10,894)$. Stage 0-I at EAC diagnosis accounted the lowest total costs. For stage 0-I, $16 \%$ of the total costs in the initial phase $(\$ 804 ; 95 \% \mathrm{CI}$, $\$ 626-\$ 982), 13 \%$ in the continuing care phase (\$646; $95 \% \mathrm{CI}, \$ 481-\$ 810)$, and $83 \%$ in the terminal phase (\$4249; 95\% CI, \$1789-\$6710) (Table 4 and see Additional file 6: Figure S3a-S3d).

The mean net costs per 30 patient-days of patients receiving radiotherapy alone was highest in the initial phase (\$1330; 95\% CI, \$1187-\$1474) followed by surgery plus chemotherapy plus radiotherapy $(\$ 1323 ; 95 \% \mathrm{CI}$, $\$ 757-\$ 1890)$, chemotherapy plus radiotherapy (\$1129; 95\% CI, (\$909-\$1350), chemotherapy alone (\$1109; 95\% CI, \$935-\$1282), surgery plus chemotherapy (\$1089; 95\% CI, \$862-\$1316), surgery plus radiotherapy (\$1080; $95 \%$ CI, \$494-\$1667), and surgery alone (\$996; 95\% CI, $\$ 856-\$ 1135)$. The mean costs of patients receiving surgery plus chemotherapy $(\$ 878 ; 95 \% \mathrm{CI}, \$ 634-\$ 1123)$ were highest in the continuing care phase followed by surgery alone (\$868; 95\% CI, \$690-\$1046) and chemotherapy plus radiotherapy ( $\$ 846 ; 95 \% \mathrm{CI}, \$ 650-\$ 1042)$. The mean costs of patients that received surgery plus radiotherapy were highest in the terminal phase $(\$ 12,237 ; 95 \% \mathrm{CI}$, $\$ 1541-\$ 22,933)$ followed by those not receiving treatment $(\$ 10,238 ; 95 \% \mathrm{CI}, \$ 9512-\$ 10,965)$ and those receiving chemotherapy alone (\$8168; 95\% CI, \$7091-\$9245) (Table 4 and see Additional file 7: Figure S4a-S4d). 
Table 1 Matched cases (esophageal adenocarcinoma) and controls by phase of care, 2003-2011

\begin{tabular}{|c|c|c|c|c|c|c|}
\hline \multirow[t]{3}{*}{ Variable } & \multicolumn{2}{|l|}{ Initial Phase } & \multicolumn{2}{|c|}{ Continuing Care Phase } & \multicolumn{2}{|c|}{ Terminal Phase } \\
\hline & Cases & Controls & Cases & Controls & Cases & Controls \\
\hline & N (\%) & N (\%) & N (\%) & N (\%) & N (\%) & N (\%) \\
\hline N & 1265 & 1265 & 632 & 632 & 3011 & 3011 \\
\hline Mean \pm SD time spent (days) & $259 \pm 130$ & $360 \pm 34$ & $726 \pm 691$ & $1521 \pm 892$ & $242 \pm 130$ & $360 \pm 36$ \\
\hline \multicolumn{7}{|l|}{ Age group at index date (years) } \\
\hline$<50$ & $106(8.4)$ & $106(8.4)$ & $53(8.4)$ & $53(8.4)$ & $242(8.0)$ & $242(8.0)$ \\
\hline $50-54$ & $138(10.9)$ & $138(10.9)$ & $76(12.0)$ & $76(12.0)$ & $277(9.2)$ & $277(9.2)$ \\
\hline $55-59$ & $165(13.0)$ & $165(13.0)$ & $84(13.3)$ & $84(13.3)$ & $331(11.0)$ & $331(11.0)$ \\
\hline $60-64$ & $227(17.9)$ & $227(17.9)$ & $116(18.4)$ & $116(18.4)$ & $459(15.2)$ & $459(15.2)$ \\
\hline $65-69$ & $203(16.1)$ & $203(16.1)$ & $113(17.9)$ & $113(17.9)$ & $423(14.1)$ & $423(14.1)$ \\
\hline $70-74$ & $161(12.7)$ & $161(12.7)$ & 86 (13.6) & 86 (13.6) & $413(13.7)$ & $413(13.7)$ \\
\hline $75-79$ & $138(10.9)$ & $138(10.9)$ & $66(10.4)$ & $66(10.4)$ & $383(12.7)$ & $383(12.7)$ \\
\hline $80-84$ & $79(6.3)$ & $79(6.3)$ & $24(3.8)$ & $24(3.8)$ & $279(9.3)$ & $279(9.3)$ \\
\hline$\geq 85$ & $48(3.8)$ & $48(3.8)$ & $14(2.2)$ & $14(2.2)$ & $204(6.8)$ & $204(6.8)$ \\
\hline \multicolumn{7}{|l|}{ Gender } \\
\hline Female & $198(15.7)$ & $198(15.7)$ & 86 (13.6) & 86 (13.6) & 499 (16.6) & 499 (16.6) \\
\hline Male & $1067(84.4)$ & $1067(84.4)$ & $546(86.4)$ & $546(86.4)$ & $2512(83.4)$ & $2512(83.4)$ \\
\hline \multicolumn{7}{|l|}{ Residence } \\
\hline Urban & $1033(81.7)$ & $1045(82.6)$ & $518(82.0)$ & $529(83.7)$ & $2464(81.8)$ & $2498(83.0)$ \\
\hline Rural & $232(18.3)$ & $220(17.4)$ & $114(18.0)$ & $103(16.3)$ & $547(18.2)$ & $513(17.0)$ \\
\hline \multicolumn{7}{|l|}{ Income quintile } \\
\hline Q1 (lowest) & $239(18.9)$ & $250(19.8)$ & $109(17.3)$ & $118(18.7)$ & $598(19.9)$ & $636(21.1)$ \\
\hline Q2 & $247(19.5)$ & $251(19.8)$ & $111(17.6)$ & $121(19.2)$ & $629(20.9)$ & $616(20.5)$ \\
\hline Q3 & $242(19.1)$ & $228(18.0)$ & $121(19.2)$ & $108(17.1)$ & $587(19.5)$ & $566(18.8)$ \\
\hline Q4 & $274(21.7)$ & $278(22.0)$ & $140(22.2)$ & $139(22.0)$ & $623(20.7)$ & $646(21.5)$ \\
\hline Q5 (highest) & $263(20.8)$ & $258(20.4)$ & $151(23.9)$ & $146(23.1)$ & $574(19.1)$ & $547(18.2)$ \\
\hline \multicolumn{7}{|l|}{ Ontario health region } \\
\hline Erie St. Clair & $65(5.1)$ & $65(5.1)$ & $35(5.5)$ & $37(5.9)$ & $153(5.1)$ & $149(5.0)$ \\
\hline South West & $88(7.0)$ & $89(7.0)$ & $40(6.3)$ & $42(6.7)$ & $273(9.1)$ & $275(9.1)$ \\
\hline Waterloo Wellington & $72(5.7)$ & $73(5.8)$ & $31(4.9)$ & $33(5.2)$ & $174(5.8)$ & $169(5.6)$ \\
\hline Hamilton Niagara Haldimand Brant & $174(13.8)$ & $178(14.1)$ & $80(12.7)$ & $84(13.3)$ & $445(14.8)$ & $450(15.0)$ \\
\hline Central West & $51(4.0)$ & $47(3.7)$ & $31(4.9)$ & $30(4.8)$ & $101(3.4)$ & $89(3.0)$ \\
\hline Mississauga & $56(4.4)$ & $57(4.5)$ & $26(4.1)$ & $26(4.1)$ & $140(4.7)$ & $145(4.8)$ \\
\hline Toronto Central & $78(6.2)$ & $82(6.5)$ & $38(6.0)$ & $40(6.3)$ & $199(6.6)$ & $207(6.9)$ \\
\hline Central & $103(8.1)$ & $103(8.1)$ & $59(9.3)$ & $59(9.3)$ & $214(7.1)$ & $215(7.1)$ \\
\hline Central East & $138(10.9)$ & $134(10.6)$ & $72(11.4)$ & $67(10.6)$ & $342(11.4)$ & $339(11.3)$ \\
\hline South East & $94(7.4)$ & $89(7.0)$ & $48(7.6)$ & $44(7.0)$ & $210(7.0)$ & $203(6.7)$ \\
\hline Champlain & $168(13.3)$ & $170(13.4)$ & $83(13.1)$ & $79(12.5)$ & $338(11.2)$ & $351(11.7)$ \\
\hline North Simcoe Muskoka & $64(5.1)$ & $70(5.5)$ & $34(5.4)$ & $40(6.3)$ & $146(4.9)$ & $155(5.2)$ \\
\hline North East & $79(6.3)$ & $78(6.2)$ & $38(6.0)$ & $35(5.5)$ & $193(6.4)$ & $194(6.4)$ \\
\hline North West & $35(2.8)$ & $30(2.4)$ & $17(2.7)$ & $16(2.5)$ & $83(2.8)$ & $70(2.3)$ \\
\hline \multicolumn{7}{|l|}{ ADGs } \\
\hline 0 & $4(0.3)$ & $4(0.3)$ & $3(0.5)$ & $3(0.5)$ & $15(0.5)$ & $15(0.5)$ \\
\hline $1-3$ & $49(3.9)$ & $49(3.9)$ & $21(3.3)$ & $21(3.3)$ & $117(3.9)$ & $117(3.9)$ \\
\hline
\end{tabular}


Table 1 Matched cases (esophageal adenocarcinoma) and controls by phase of care, 2003-2011 (Continued)

\begin{tabular}{|c|c|c|c|c|c|c|}
\hline \multirow[t]{3}{*}{ Variable } & \multicolumn{2}{|c|}{ Initial Phase } & \multicolumn{2}{|c|}{ Continuing Care Phase } & \multicolumn{2}{|c|}{ Terminal Phase } \\
\hline & Cases & Controls & Cases & Controls & Cases & Controls \\
\hline & N (\%) & N (\%) & N (\%) & N (\%) & N (\%) & N (\%) \\
\hline $4-7$ & 235 (18.6) & 235 (18.6) & 118 (18.7) & $118(18.7)$ & $549(18.2)$ & $549(18.2)$ \\
\hline $8-10$ & $341(27.0)$ & $341(27.0)$ & $155(24.5)$ & $154(24.5)$ & $803(26.7)$ & $803(26.7)$ \\
\hline $11+$ & $636(50.3)$ & $636(50.3)$ & $335(53.0)$ & $335(53.0)$ & $1527(50.7)$ & $1527(50.7)$ \\
\hline \multicolumn{7}{|c|}{ Year of EAC diagnosis } \\
\hline 2003 & $118(9.3)$ & $118(9.3)$ & $59(9.3)$ & $57(9.3)$ & $284(9.4)$ & $284(9.4)$ \\
\hline 2004 & $126(10.0)$ & $126(10.0)$ & $74(11.7)$ & $74(11.7)$ & $288(9.6)$ & $288(9.6)$ \\
\hline 2005 & $97(7.7)$ & $97(7.7)$ & $63(10.0)$ & $63(10.0)$ & $279(9.3)$ & $279(9.3)$ \\
\hline 2006 & $139(11.0)$ & $139(11.0)$ & $71(11.2)$ & $71(11.2)$ & $320(10.6)$ & $320(10.6)$ \\
\hline 2007 & $122(9.6)$ & $122(9.6)$ & $64(10.1)$ & $64(10.1)$ & $297(9.9)$ & $297(9.9)$ \\
\hline 2008 & $139(11.0)$ & $139(11.0)$ & $81(12.8)$ & $81(12.8)$ & $349(11.6)$ & 349 (11.6) \\
\hline 2009 & $165(13.0)$ & $165(13.0)$ & $90(14.2)$ & $90(14.2)$ & $386(12.8)$ & $386(12.8)$ \\
\hline 2010 & $181(14.3)$ & $181(14.3)$ & 85 (13.5) & 85 (13.5) & $397(13.2)$ & $397(13.2)$ \\
\hline 2011 & $178(14.1)$ & $178(14.1)$ & $45(7.1)$ & $45(7.1)$ & 411 (13.7) & $411(13.7)$ \\
\hline
\end{tabular}

SD standard deviation, ADGs Aggregated Diagnosis Groups, EAC esophageal adenocarcinoma

\section{Predictors of total net costs of care in individuals diagnosed with EAC}

Univariate and multivariate predictors of total net costs of care in individuals diagnosed with EAC are summarized in Tables 5 and 6. Several patient characteristics were significant predictors of total net costs of care per 30 patient-days. In the initial phase, predictors of higher costs associated with EAC included all stages at EAC diagnosis compared with stage 0 -I $(P<0.001)$, all treatments for EAC except surgery plus radiotherapy compared with no treatment $(P<0.001)$, and year of EAC diagnosis from 2006 to 2011 compared with $2003(P<0.001)$ (Table 6). The multivariate coefficients for stage indicate in the initial phase, stage III compared to stage $0-1$ cost $\$ 1.51$ more per 30 patient-days controlling for other factors. Patients diagnosed with EAC on 2011 compared to 2003 cost $\$ 2.41$ more per 30 patient-days, after controlling for other factors. Patients who received surgery plus chemotherapy plus radiotherapy were associated with $\$ 2.57$ increase in cost per 30 patient-days compared to the no treatment group controlling for all other factors.

In the continuing care phase, predictors of higher cost associated with EAC included comorbidity measured by the Johns Hopkins ADGs (from ADGs 1-3 to ADGs 11+ compared with no comorbidity, $P<0.001$ ) and all treatments for EAC except surgery plus radiotherapy and

Table 2 Mean health care costs ${ }^{a}$ among EAC cases and non-EAC controls according to service category and phase of care, $2003-2011$

\begin{tabular}{|c|c|c|c|c|c|c|}
\hline \multirow[t]{3}{*}{ Service category } & \multicolumn{2}{|l|}{ Initial Phase } & \multicolumn{2}{|c|}{ Continuing Care Phase } & \multicolumn{2}{|l|}{ Terminal Phase } \\
\hline & Cases & Controls & Cases & Controls & Cases & Controls \\
\hline & Mean $(95 \% \mathrm{Cl})$ & Mean $(95 \% \mathrm{Cl})$ & Mean $(95 \% \mathrm{Cl})$ & Mean $(95 \% \mathrm{Cl})$ & Mean $(95 \% \mathrm{Cl})$ & Mean $(95 \% \mathrm{Cl})$ \\
\hline N & 1285 & 2942 & 651 & 2870 & 3011 & 3011 \\
\hline Outpatient visits & $\$ 170(\$ 164-\$ 177)$ & $\$ 16(\$ 15-\$ 17)$ & $\$ 157(\$ 150-\$ 165)$ & $\$ 40(\$ 38-\$ 42)$ & $\$ 1263(\$ 1199-\$ 1327)$ & $\$ 37(\$ 25-\$ 49)$ \\
\hline $\begin{array}{l}\text { Emergency department } \\
\text { visits }\end{array}$ & $\$ 20(\$ 19-\$ 22)$ & $\$ 3(\$ 3-\$ 4)$ & $\$ 17(\$ 15-\$ 18)$ & $\$ 8(\$ 7-\$ 8)$ & $\$ 218(\$ 197-\$ 240)$ & $\$ 11(\$ 8-\$ 13)$ \\
\hline Same-day surgery & $\$ 32(\$ 30-\$ 34)$ & $\$ 3(\$ 2-\$ 3)$ & $\$ 35(\$ 32-\$ 37)$ & $\$ 8(\$ 7-\$ 8)$ & $\$ 170(\$ 156-\$ 185)$ & $\$ 3(\$ 3-\$ 3)$ \\
\hline Inpatient hospitalization & $\$ 491(\$ 452-\$ 530)$ & $\$ 36(\$ 30-\$ 42)$ & $\$ 404(\$ 357-\$ 451)$ & $\$ 60(\$ 55-\$ 66)$ & $\$ 5451(\$ 5084-\$ 5818)$ & $\$ 154(\$ 109-\$ 198)$ \\
\hline Medications & $\$ 63(\$ 58-\$ 68)$ & $\$ 17(\$ 15-\$ 18)$ & $\$ 65(\$ 58-\$ 73)$ & $\$ 43(\$ 40-\$ 46)$ & $\$ 247(\$ 231-\$ 264)$ & $\$ 23(\$ 21-\$ 25)$ \\
\hline Home care & $\$ 86(\$ 79-\$ 93)$ & $\$ 7(\$ 6-\$ 8)$ & $\$ 61(\$ 54-\$ 68)$ & $\$ 14(\$ 12-\$ 16)$ & $\$ 467(\$ 440-\$ 494)$ & $\$ 17(\$ 8-\$ 27)$ \\
\hline Continuing care & $\$ 5(\$ 1-\$ 8)$ & $\$ 11(\$ 8-\$ 14)$ & $\$ 4(-\$ 1-\$ 8)$ & $\$ 22(\$ 17-\$ 27)$ & $\$ 20(\$ 10-\$ 29)$ & $\$ 23(\$ 14-\$ 31)$ \\
\hline Long-term care & $\$ 9(\$ 5-\$ 14)$ & $\$ 20(\$ 16-\$ 24)$ & $\$ 8(\$ 2-\$ 14)$ & $\$ 32(\$ 25-\$ 38)$ & $\$ 43(\$ 31-\$ 55)$ & $\$ 42(\$ 32-\$ 53)$ \\
\hline Total cost & $\$ 1139(\$ 1079-\$ 1199)$ & $\$ 122(\$ 110-\$ 135)$ & $\$ 923(\$ 852-\$ 995)$ & $\$ 254(\$ 232-\$ 276)$ & $\$ 9004(\$ 8545-\$ 9462)$ & $\$ 326(\$ 265-\$ 387)$ \\
\hline
\end{tabular}

EAC esophageal adenocarcinoma, $\mathrm{Cl}$ confidence intervals

${ }^{\mathrm{a}}$ Mean health care costs are expressed in 2016 Canadian dollars per 30 patient-days 
Table 3 Mean net costs ${ }^{a}$ of care due to esophageal adenocarcinoma according to service category and phase of care, 2003-2011

\begin{tabular}{|c|c|c|c|c|}
\hline \multirow[t]{2}{*}{ Service category } & Overall & Initial Phase & Continuing Care Phase & Terminal Phase \\
\hline & Mean $(95 \% \mathrm{Cl})$ & Mean $(95 \% \mathrm{Cl})$ & Mean $(95 \% \mathrm{Cl})$ & Mean $(95 \% \mathrm{Cl})$ \\
\hline N & 6022 & 4227 & 3521 & 6022 \\
\hline Outpatient visits & $\$ 1279(\$ 1215-\$ 1343)$ & $\$ 155(\$ 148-\$ 162)$ & $\$ 117(\$ 109-\$ 125)$ & $\$ 1226(\$ 1161-\$ 1291)$ \\
\hline Emergency department visits & $\$ 209(\$ 188-\$ 231)$ & $\$ 17(\$ 16-\$ 18)$ & $\$ 9(\$ 8-\$ 11)$ & $\$ 208(\$ 186-\$ 230)$ \\
\hline Same-day surgery & $\$ 179(\$ 164-\$ 193)$ & $\$ 29(\$ 27-\$ 31)$ & $\$ 27(\$ 24-\$ 30)$ & $\$ 167(\$ 153-\$ 182)$ \\
\hline Inpatient hospitalization & $\$ 5501(\$ 5135-\$ 5867)$ & $\$ 455(\$ 415-\$ 494)$ & $\$ 343(\$ 296-\$ 390)$ & $\$ 5297(\$ 4929-\$ 5665)$ \\
\hline Medications & $\$ 207(\$ 190-\$ 225)$ & $\$ 46(\$ 41-\$ 51)$ & $\$ 22(\$ 14-\$ 30)$ & $\$ 224(\$ 208-\$ 240)$ \\
\hline Home care & $\$ 479(\$ 450-\$ 509)$ & $\$ 79(\$ 72-\$ 86)$ & $\$ 47(\$ 39-\$ 55)$ & $\$ 449(\$ 421-\$ 478)$ \\
\hline Continuing care & $-\$ 32(-\$ 47--\$ 17)$ & $-\$ 7(-\$ 11--\$ 2)$ & $-\$ 18(-\$ 25--\$ 12)$ & $-\$ 3(-\$ 15-\$ 9)$ \\
\hline Long-term care & $-\$ 44(-\$ 64--\$ 24)$ & $-\$ 11(-\$ 17--\$ 4)$ & $-\$ 24(-\$ 33--\$ 15)$ & $\$ 0(-\$ 15-\$ 16)$ \\
\hline Total net costs & $\$ 9002(\$ 8547-\$ 9456)$ & $\$ 1016(\$ 955-\$ 1078)$ & $\$ 669(\$ 594-\$ 743)$ & $\$ 8678(\$ 8217-\$ 9139)$ \\
\hline
\end{tabular}

Net costs of care due to esophageal adenocarcinoma were generated using generalized estimating equations

EAC esophageal adenocarcinoma, $\mathrm{Cl}$ confidence intervals

${ }^{a}$ Mean health care costs are expressed in 2016 Canadian dollars per 30 patient-days

Table 4 Overall and phase of care net cost of health care resources by stage at diagnosis and treatment type for the esophageal adenocarcinoma cohort, 2003-2011

\begin{tabular}{|c|c|c|c|c|c|c|c|}
\hline \multirow[t]{2}{*}{ Cost category } & \multicolumn{2}{|l|}{ Overall } & \multicolumn{2}{|l|}{ Initial Phase } & \multicolumn{2}{|c|}{ Continuing Care Phase } & \multirow{2}{*}{$\begin{array}{l}\text { Terminal Phase } \\
\text { Mean }^{a}(95 \% \mathrm{Cl})\end{array}$} \\
\hline & Mean ${ }^{\mathrm{a}}(95 \% \mathrm{Cl})$ & N (Cases) & Mean $^{\mathrm{a}}(95 \% \mathrm{Cl})$ & N (Cases) & Mean $^{\mathrm{a}}(95 \% \mathrm{Cl})$ & $\mathrm{N}$ (Cases) & \\
\hline \multicolumn{8}{|l|}{ Stage at EAC diagnosis } \\
\hline Stage $0-$ I & $\begin{array}{l}\$ 5094 \\
(\$ 2659-\$ 7529)\end{array}$ & 102 & $\begin{array}{l}\$ 804 \\
(\$ 626-\$ 982)\end{array}$ & 64 & $\begin{array}{l}\$ 646 \\
(\$ 481-\$ 810)\end{array}$ & 126 & $\begin{array}{l}\$ 4249 \\
(\$ 1789-\$ 6710)\end{array}$ \\
\hline Stage II & $\begin{array}{l}\$ 6192 \\
(\$ 5368-\$ 7015)\end{array}$ & 282 & $\begin{array}{l}\$ 999 \\
(\$ 887-\$ 1111)\end{array}$ & 161 & $\begin{array}{l}\$ 696 \\
(\$ 600-\$ 791)\end{array}$ & 416 & $\begin{array}{l}\$ 5426 \\
(\$ 4574-\$ 6277)\end{array}$ \\
\hline Stage III & $\begin{array}{l}\$ 7413 \\
(\$ 6679-\$ 8147)\end{array}$ & 273 & $\begin{array}{l}\$ 1254 \\
(\$ 1142-\$ 1366)\end{array}$ & 136 & $\begin{array}{l}\$ 708 \\
(\$ 565-\$ 851)\end{array}$ & 451 & $\begin{array}{l}\$ 6652 \\
(\$ 5879-\$ 7425)\end{array}$ \\
\hline Stage IV & $\begin{array}{l}\$ 9978 \\
(\$ 9093-\$ 10,864)\end{array}$ & 222 & $\begin{array}{l}\$ 1010 \\
(\$ 887-\$ 1134)\end{array}$ & 74 & $\begin{array}{l}\$ 620 \\
(\$ 461-\$ 780)\end{array}$ & 930 & $\begin{array}{l}\$ 10,000 \\
(\$ 9106-\$ 10,894)\end{array}$ \\
\hline \multicolumn{8}{|l|}{ Type of EAC treatment } \\
\hline Surgery alone & $\begin{array}{l}\$ 7785 \\
(\$ 6667-\$ 8903)\end{array}$ & 361 & $\begin{array}{l}\$ 996 \\
(\$ 856-\$ 1135)\end{array}$ & 215 & $\begin{array}{l}\$ 868 \\
(\$ 690-\$ 1046)\end{array}$ & 533 & $\begin{array}{l}\$ 6937 \\
(\$ 5802-\$ 8071)\end{array}$ \\
\hline Chemotherapy alone & $\begin{array}{l}\$ 8607 \\
(\$ 7565-\$ 9650)\end{array}$ & 161 & $\$ 1109(\$ 935-\$ 1282)$ & 86 & $\begin{array}{l}\$ 590 \\
(\$ 466-\$ 715)\end{array}$ & 338 & $\begin{array}{l}\$ 8168 \\
(\$ 7091-\$ 9245)\end{array}$ \\
\hline Radiotherapy alone & $\begin{array}{l}\$ 7998 \\
(\$ 7095-\$ 8901)\end{array}$ & 228 & $\begin{array}{l}\$ 1330 \\
(\$ 1187-\$ 1474)\end{array}$ & 118 & $\begin{array}{l}\$ 630 \\
(\$ 518-\$ 742)\end{array}$ & 405 & $\begin{array}{l}\$ 7285 \\
(\$ 6344-\$ 8225)\end{array}$ \\
\hline Surgery + chemotherapy & $\begin{array}{l}\$ 5801 \\
(\$ 4751-\$ 6850)\end{array}$ & 81 & $\begin{array}{l}\$ 1089 \\
(\$ 862-\$ 1316)\end{array}$ & 52 & $\begin{array}{l}\$ 878 \\
(\$ 634-\$ 1123)\end{array}$ & 118 & $\begin{array}{l}\$ 4832 \\
(\$ 3710-\$ 5954)\end{array}$ \\
\hline Surgery + radiotherapy & $\begin{array}{l}\$ 12,417 \\
(\$ 2067-\$ 22,767)\end{array}$ & - & $\begin{array}{l}\$ 1080 \\
(\$ 494-\$ 1667)\end{array}$ & - & $\begin{array}{l}\$ 170 \\
(-\$ 200-\$ 539)\end{array}$ & 6 & $\begin{array}{l}\$ 12,237 \\
(\$ 1541-\$ 22,933)\end{array}$ \\
\hline Chemotherapy + radiotherapy & $\begin{array}{l}\$ 7671 \\
(\$ 6023-\$ 9320)\end{array}$ & 68 & $\begin{array}{l}\$ 1129 \\
(\$ 909-\$ 1350)\end{array}$ & 40 & $\begin{array}{l}\$ 846 \\
(\$ 650-\$ 1042)\end{array}$ & 109 & $\begin{array}{l}\$ 6849 \\
(\$ 5107-\$ 8590)\end{array}$ \\
\hline $\begin{array}{l}\text { Surgery + chemotherapy } \\
+ \text { radiotherapy }\end{array}$ & $\begin{array}{l}\$ 4743 \\
(\$ 1755-\$ 7731)\end{array}$ & 7 & $\begin{array}{l}\$ 1323 \\
(\$ 757-\$ 1890)\end{array}$ & - & $\begin{array}{l}\$ 236 \\
(\$ 111-\$ 362)\end{array}$ & 7 & $\begin{array}{l}\$ 3519 \\
(\$ 684-\$ 6354)\end{array}$ \\
\hline No treatment & $\begin{array}{l}\$ 10,152 \\
(\$ 9431-\$ 10,873)\end{array}$ & 377 & $\begin{array}{l}\$ 765 \\
(\$ 688-842)\end{array}$ & 136 & $\begin{array}{l}\$ 318 \\
(\$ 243-\$ 393)\end{array}$ & 1495 & $\begin{array}{l}\$ 10,238 \\
(\$ 9512-\$ 10,965)\end{array}$ \\
\hline
\end{tabular}

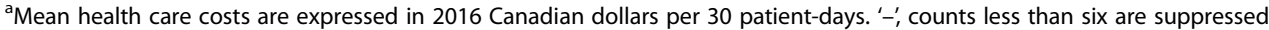
$E A C$ esophageal adenocarcinoma, $\mathrm{Cl}$ confidence intervals 


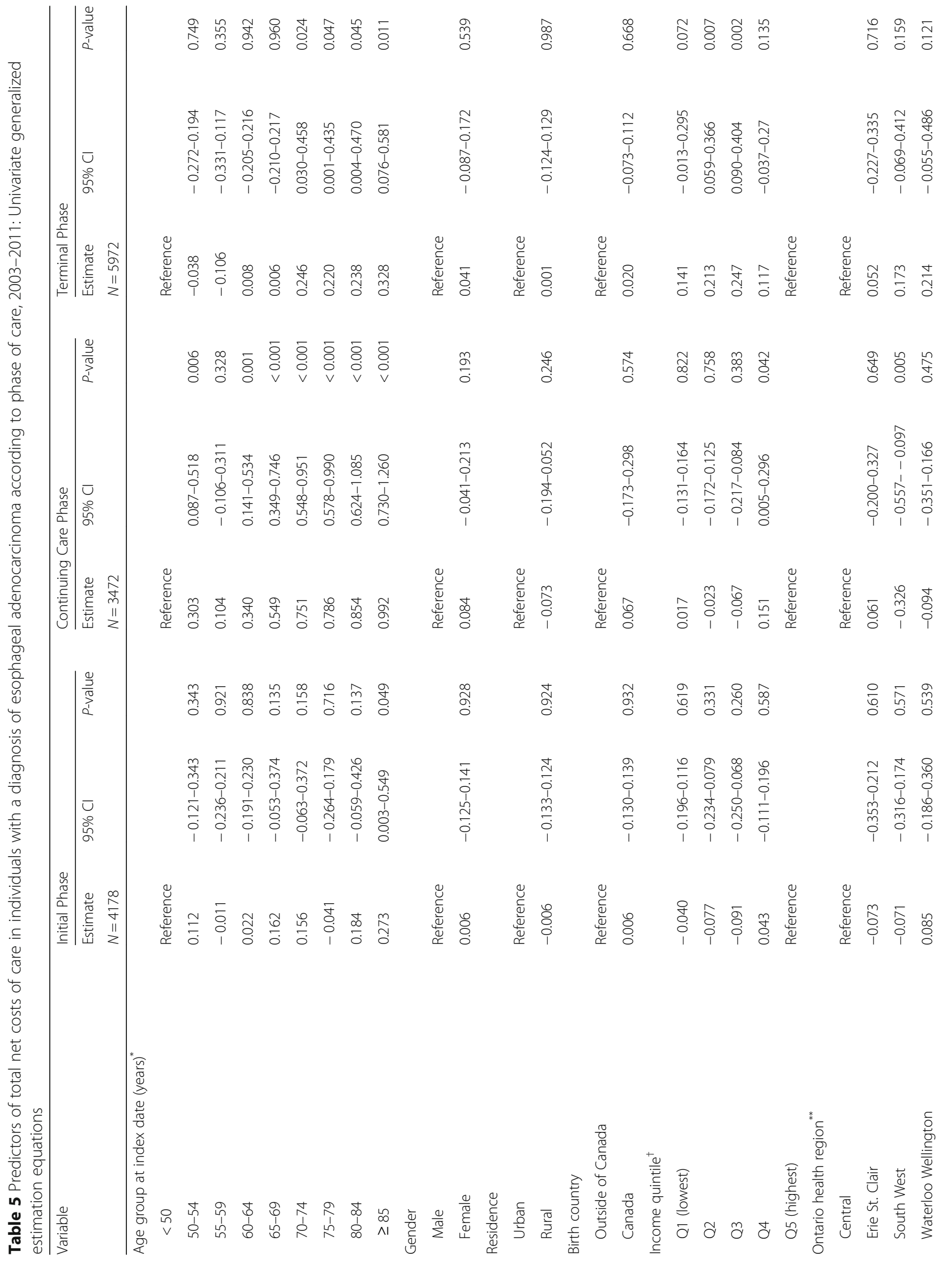




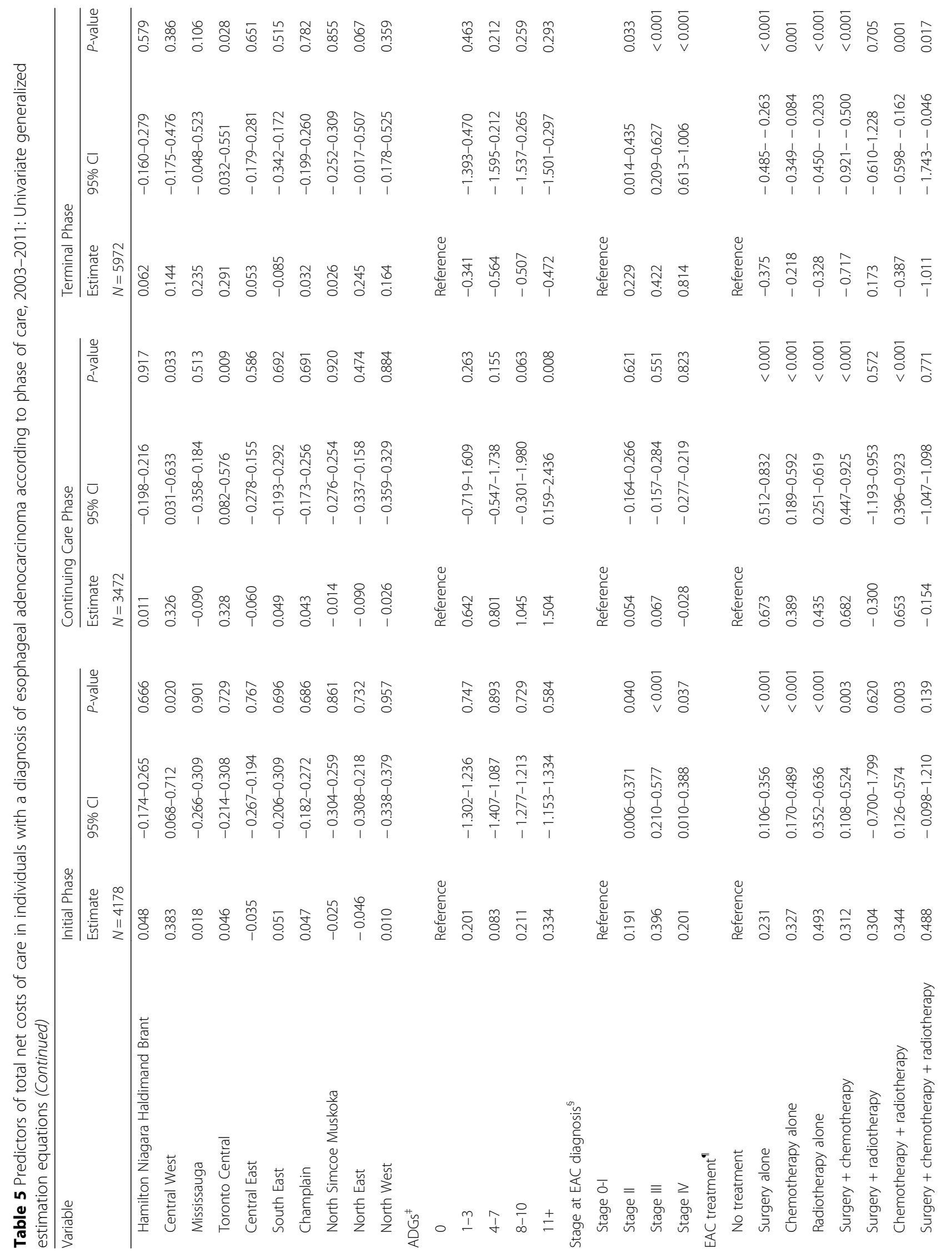




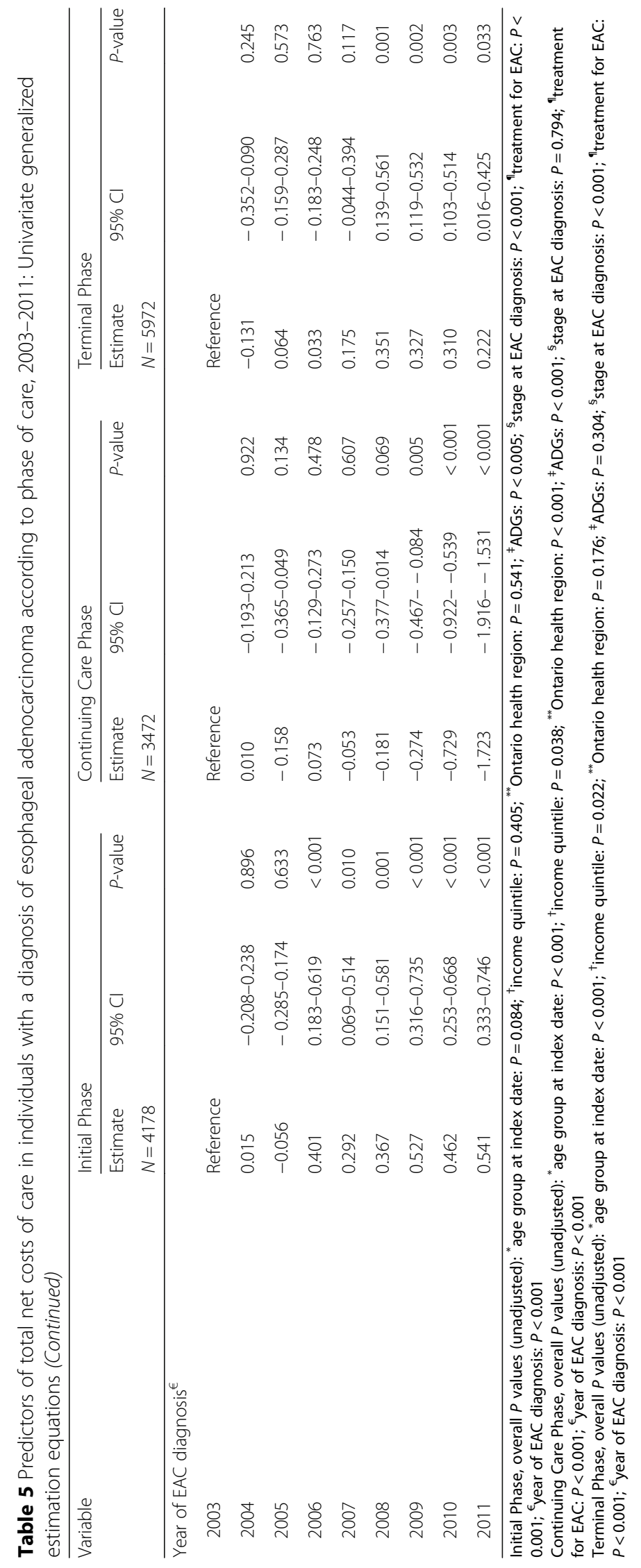




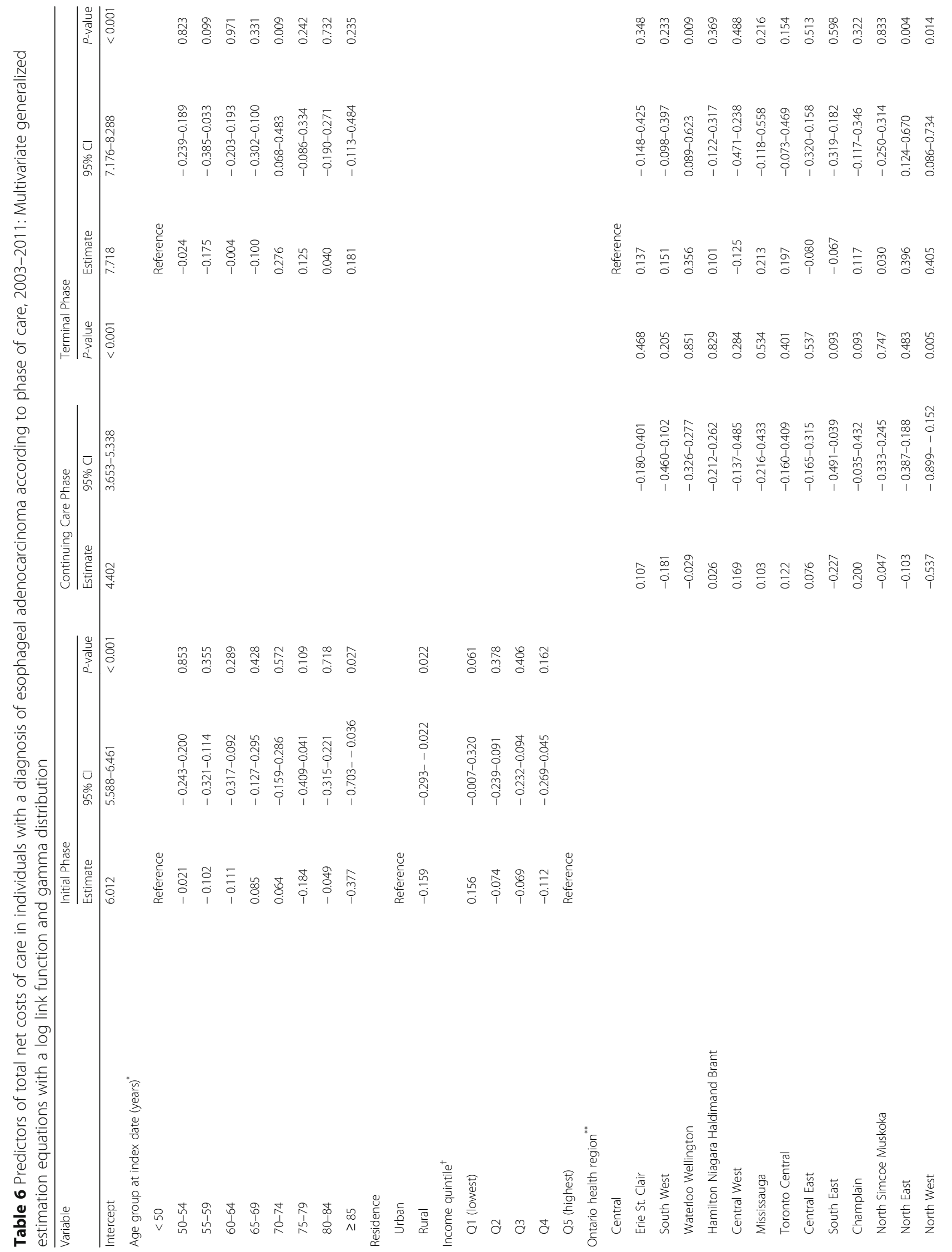




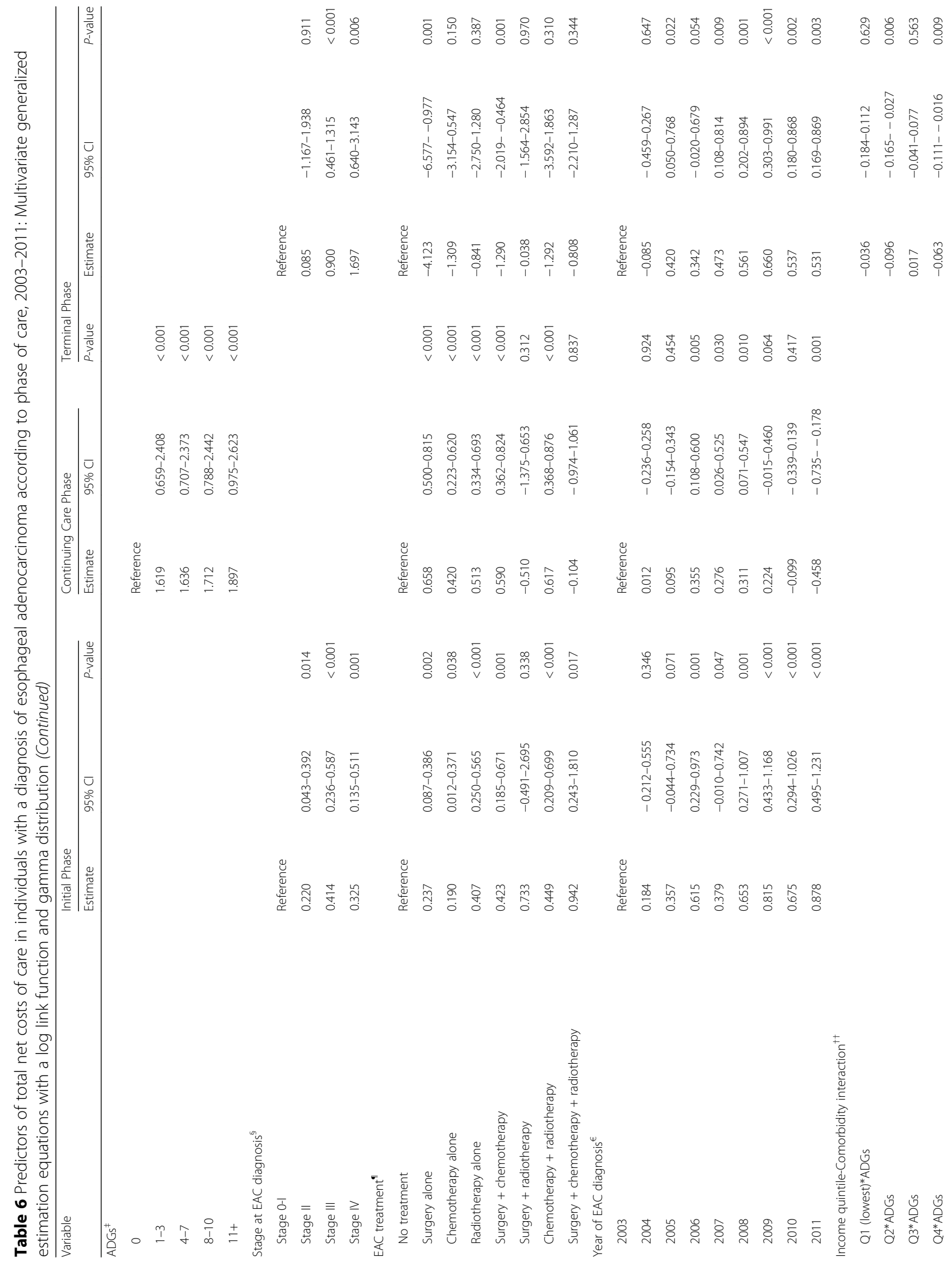









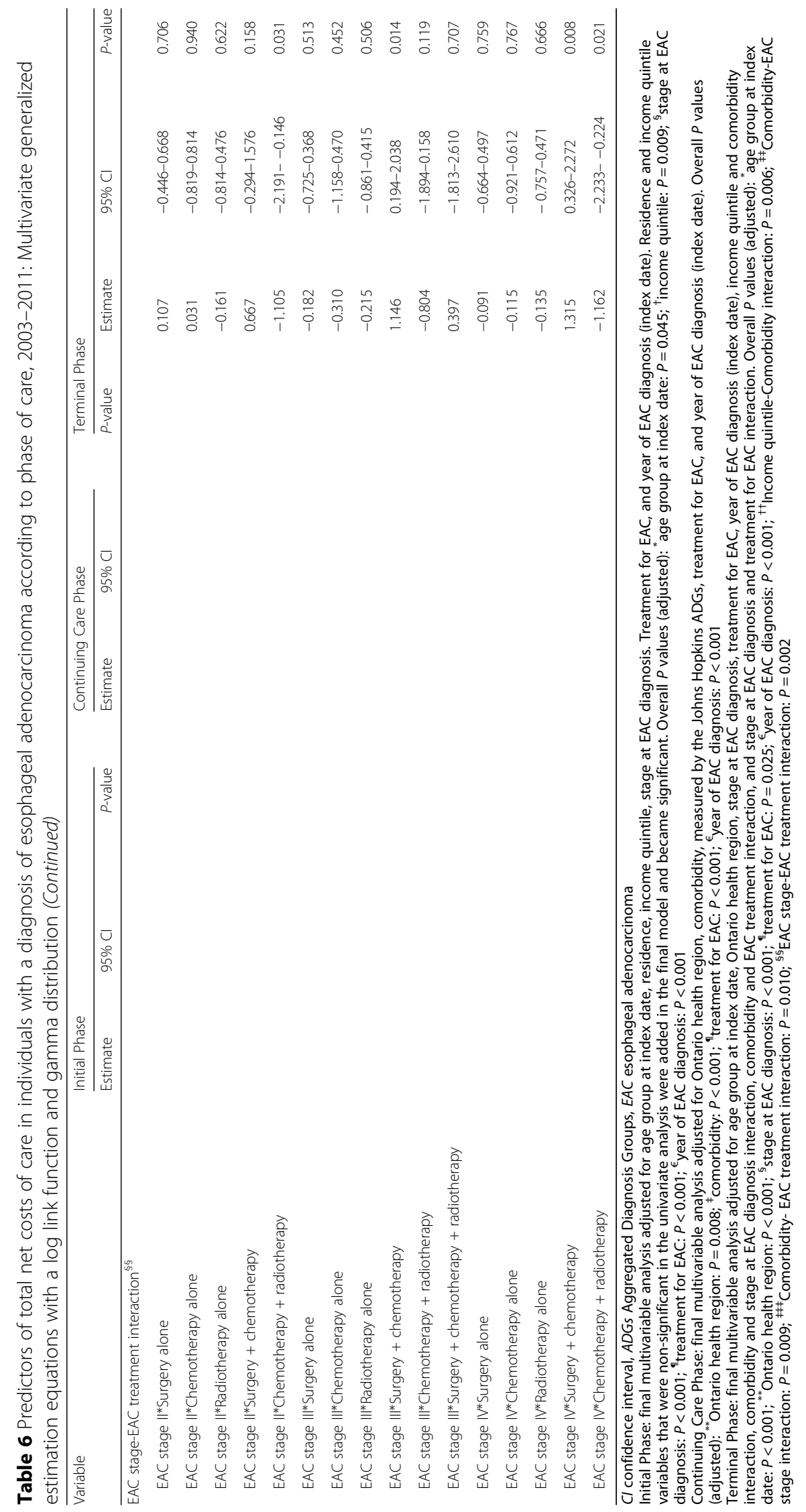


surgery plus chemotherapy plus radiotherapy $(P<0.001)$, and year of EAC diagnosis from 2006 to $2008(P<0.05)$.

In the terminal phase, predictors of higher cost associated with EAC included 70-74 years of age at index date $(P=0.009)$, Ontario health region (Waterloo Wellington, $P=0.009$; North East, $P=0.004$; and North West, $P=$ 0.014), stage III $(P<0.001)$ and stage IV $(P=0.006)$ at EAC diagnosis, year of EAC diagnosis from 2005 to 2011 (except 2006; $P<0.001$ ), comorbidity (ADGs $1-3,4-7,8-10$ and $11+)$ and surgery alone interaction $(P=0.001, P=$ $0.004, P=0.002$ and $P=0.001$, respectively), comorbidity (ADGs $8-10)$ and chemotherapy plus radiotherapy interaction $(P=0.027)$ and EAC stage-EAC surgery plus chemotherapy interactions (stage III, $P=0.014$ ) and stage IV $(P=0.008)$ (Table 6). In the terminal phase, patients in stage IV were associated with $\$ 5.46$ increase in cost per 30 patient-days compared to those in stage $0-1$ controlling for other factors.

\section{Sensitivity analysis}

In the sensitivity analysis assigning 6 months after the diagnosis to the initial phase and 6 months preceding death to the terminal phase, there was a significant increase $(85 \%)$ in the total net costs of care in the continuing care phase and a modest increase $(42 \%)$ in the initial phase compared with the total net costs of care in the primary analysis (Additional file 8: Table S5). The mean net costs of surgery plus radiotherapy (108\%) and all treatments significantly increased in the initial phase (23-108\%) and continuing care phase (63-639\%), respectively compared with the primary analysis (Additional file 8: Table S6). Predictors of total net costs of care associated with EAC were similar to the primary analysis in the terminal phase (Additional file 8: Table S7).

\section{Discussion}

This population-based retrospective cohort study examined phase-specific net costs of care per 30 patient-days attributable to EAC from a public payer perspective, total net costs of care by stage and treatment for EAC, and predictors of total net costs of care in individuals diagnosed with EAC by phase of care. The aggregated total net health care costs of EAC care were highest in the terminal phase, next highest in the initial phase, and the lowest cost was in the continuing care phase. Inpatient hospitalizations accounted for the largest share of costs in all phases, followed by outpatient visits and home care. Overall, stage IV at diagnosis and surgery plus radiotherapy for EAC accounted for the highest cost, in particular in the terminal phase. The factors that were associated with higher net costs of care included treatment for EAC, especially chemotherapy plus radiotherapy, surgery plus chemotherapy, radiotherapy alone, surgery alone, and chemotherapy alone in the initial and continuing care phases; intermediate or advanced stage and the latest year of EAC diagnosis in the initial and terminal phases; comorbidity in the continuing care phase; and older age at diagnosis (70-74 years) and Ontario health region (Waterloo Wellington, North East, North West) in the terminal phase. Associations like older age and lower income quintile may reflect medical factors such as comorbidity, or social factors like lesser social support that could lead to higher use of medical services. Finally, lower costs were associated with individuals diagnosed with EAC included 85 years of age and older at index date and rural residence in the initial phase.

Phase-specific costs are useful for estimating incidence-based and long-term care costs, defined as cumulative costs from the date of diagnosis to death [22]. In addition, phase-specific cost estimates constitute an important input for economic evaluation of prevention, screening, and treatment interventions [21, 22, 25]. Our phase-specific costing approach provided in-depth cost analysis to the specific net phase of care costs for EAC, compared to previous studies which only looked at overall costs. Recent and past studies analyzing hospital costs after complex esophageal surgical procedures indicate that postoperative complications are associated with increased resource utilization and costs $[59,60]$. Such complications were captured in the phased costing approach we used. According to a large randomized trial, preoperative chemoradiotherapy is safe and leads to a significant increase in overall survival among patients with localized adenocarcinoma or squamous-cell carcinoma of the esophagus compared with those treated with surgery alone [61]. Esophageal cancer is often in an advanced stage when it is diagnosed, however. At later stages, esophageal cancer can be treated but not cured. The selection of prevention and treatment activities at different stages of disease can have significant impact on resource utilization [21, 62].

The strengths of our study include comprehensive cost estimation and rigorous propensity score matching between cases and controls, which was based on sociodemographic and comorbidity characteristics, providing unbiased estimates of the net costs of care. Our study results can inform publically funded health care systems on the cost of treatments for patients, considering stage and other sociodemographic and clinical patient characteristics. It can also aid detailed future planning of health care costs.

Our study has some limitations. Our cost estimates did not reflect the overall economic burden of EAC to the society. Because Ontario only provides comprehensive coverage for the elderly and those on social assistance, prescription medication costs were not included 
for patients $<65$ years. However, 1722 (56.7\%) of our patients are over age 65 years, and prescription drug costs only accounted for $10 \%$ of total costs for patients in this age group. Therefore, it is unlikely that the costs for prescription drug cost for patients under age 65 would significantly change our results. Additionally, since we matched patients on age, the missing prescription drug costs, which contributes towards the total costs, is also matched for cases and controls (patients who are matched and under 65 will not have this cost accounted for in the total compared to matched patients over the age of 65 which will have the cost included in total for cases and controls). No difference in results would be expected as the missing prescription is homogenously distributed between cases and controls. Although multiple imputation would provide a solution for missing data, in our case there is no readily available data for which to impute the cost of prescription drugs for patients under the age of 65 . Prescription drug costs for patients over the age of 65 would not be valid to impute for patients under the age of 65 . We therefore did not impute the value of prescription costs for patients with missing prescription drug costs. Moreover, a limitation of our study was that only overall cost was provided by type for patients. Individual health care costs with dates were not provided. Therefore, we were not able to investigate cost thresholds to determine cost phase boundaries and instead had to rely on previous research to determine cost phases. Furthermore, we estimated direct health care costs only and did not include patient out-of-pocket costs or loss of productivity, which are important elements of the cost of illness for society and individuals. Finally, we could not assess the effect of screening prior to Barrett's esophagus or cancer diagnosis on costs. EAC patients with a prior Barrett's esophagus diagnosis are commonly diagnosed with earlier stage disease and have improved survival compared with EAC patients with no prior Barrett's esophagus diagnosis $[63,64]$.

\section{Conclusions}

Our phase-specific longitudinal net costing approach for patients diagnosed with EAC until death identified three distinct cost phases, and found that costs were highest in the terminal phase, where inpatient hospitalization cost was the greatest contributor to total costs than in other phases. Furthermore, our findings suggest that the economic burden of EAC is significant and is expected to continue to increase due to the growth and aging of the population, the increase in the incidence of EAC, comorbidity, disease progression, and the potentially expensive treatments of the future. Further research is needed on methods to incorporate these phase-based costs into cost-effectiveness analyses for EAC treatment.

\section{Additional files}

Additional file 1: Materials and Methods. Table S1. Fee codes used to define types of treatment for esophageal adenocarcinoma. Table S2. Codes used to define cases of esophageal adenocarcinoma. (DOCX $22 \mathrm{~kb}$ )

Additional file 2: Figure S1. Flowchart describing the selection of the study population. (JPG $90 \mathrm{~kb}$ )

Additional file 3: Table S3. Demographic characteristics of esophageal adenocarcinoma cases and controls, 2003-2011. (DOCX 21 kb)

Additional file 4: Figure S2a-d. Mean net costs of health care resources due to esophageal adenocarcinoma (difference between the mean costs for esophageal adenocarcinoma cases and for matched controls without cancer) according to phase of care, 2003-2011: (a) Overall; (b) Initial Phase; (c) Continuing Care Phase; and (d) Terminal Phase. (JPG 87 kb)

Additional file 5: Table S4. Bootstrap samples for mean net costs ${ }^{*}$ of care due to esophageal adenocarcinoma according to service category and phase of care, 2003-2011. (DOCX 13 kb)

Additional file 6: Figure S3a-d. Overall and phase of care net cost of health care resources by stage at diagnosis for esophageal adenocarcinoma, 2003-2011: (a) Overall; (b) Initial Phase; (c) Continuing Care Phase; and (d) Terminal Phase. (JPG 59 kb)

Additional file 7: Figure S4a-d. Overall and phase of care net cost of health care resources by treatment type for esophageal adenocarcinoma, 2003-2011: (a) Overall; (b) Initial Phase; (c) Continuing Care Phase; and (d) Terminal Phase. (JPG 80 kb)

Additional file 8: Table S5. Mean net costs ${ }^{*}$ of care due to esophageal adenocarcinoma according to service category and phase of care, 20032011: Sensitivity analysis. Table S6. Overall and phase of care net cost of health care resources by stage at diagnosis and treatment type for the esophageal adenocarcinoma cohort, 2003-2011: Sensitivity analysis.

Table S7. Predictors of total net costs of care in individuals with a diagnosis of esophageal adenocarcinoma according to phase of care, 2003-2011: Multivariate generalized estimation equations with a log link function and gamma distribution - Sensitivity analysis. (DOCX $37 \mathrm{~kb}$ )

\section{Abbreviations}

ADGs: Aggregated Diagnosis Groups; Cl: Confidence interval; CIHI: Canadian Institute for Health Information; DAD: Discharge Abstract Database;

EAC: Esophageal adenocarcinoma; GERD: Gastroesophageal reflux disease; ICD-9: International Statistical Classification of Diseases and Related Health Problems, 9th Revision; ICD-O-3: International Classification of Diseases for Oncology, Third Edition; LHIN: Local Health Integration Network; NACRS: National Ambulatory Care Reporting System; OCR: Ontario Cancer Registry; OHIP: Ontario Health Insurance Plan

\section{Acknowledgements}

The authors thank James Lane, Nadia Gunraj, Nelson Chong, Refik Saskin, and Lisa Ishiguro from the Institute for Clinical and Evaluative Sciences for conducting the data linkage.

\section{Funding}

This project was funded by the Cancer Care Ontario and the Ontario Institute for Cancer Research (\#30008). This study was supported through provision of data by the Institute for Clinical Evaluative Sciences and Cancer Care Ontario and through funding support to Institute for Clinical Evaluative Sciences from an annual grant by the Ministry of Health and Long-Term Care and the Ontario Institute for Cancer Research. The opinions, results, and conclusions reported in this paper are those of the authors and are independent from the funding sources. No endorsement by Institute for Clinical Evaluative Sciences, Cancer Care Ontario, Ontario Institute for Cancer Research or the Government of Ontario is intended or should be inferred.

\section{Availability of data and materials}

The data used in this analysis are available through the Ontario Cancer Registry and the Institute for Clinical Evaluative Sciences in Toronto, Ontario, Canada. These data cannot be shared due to privacy concerns.

http://www.ices.on.ca/Data-and-Privacy. 


\section{Authors' contributions}

The first author, HHT, managed the overall project, contributed to the conception and design of the study, acquisition of data, statistical analysis, technical support, interpretation of data, drafting of the manuscript and critical revision of the manuscript for important intellectual content. NJ, KT, KKWC, PCC, CdO, CH and CCE also contributed to the conception and design of the study, interpretation of data and critical revision of the manuscript for important intellectual content; NJ also contributed statistical analysis and technical support. CCE provided material support. All authors stated that they have read the manuscript, have given final approval of the version to be published and have participated in the study to a sufficient extent to be named as authors.

\section{Ethics approval and consent to participate}

Ethics approval for the study was granted by the University of Toronto Health Sciences.

Research Ethics Board. Informed consent was not obtained because this secondary analysis.

accessed existing de-identified data; consent was therefore deemed to be neither feasible nor.

necessary.

\section{Consent for publication}

Not applicable.

\section{Competing interests}

The authors declare that they have no competing interests.

\section{Publisher's Note}

Springer Nature remains neutral with regard to jurisdictional claims in published maps and institutional affiliations.

\section{Author details}

'Dalla Lana School of Public Health, University of Toronto, Toronto, ON, Canada. ${ }^{2}$ Institute for Clinical Evaluative Sciences, Toronto, ON, Canada. ${ }^{3}$ Ottawa Hospital Research Institute, The Ottawa Hospital, Ottawa, ON, Canada. ${ }^{4}$ School of Epidemiology, Public Health and Preventive Medicine, University of Ottawa, Ottawa, ON, Canada. ${ }^{5}$ Institute for Clinical Evaluative Sciences (ICES uOttawa), Ottawa, ON, Canada. ${ }^{6}$ Department of Medicine, University of Toronto, Toronto, ON, Canada. ${ }^{7}$ Odette Cancer Centre, Sunnybrook Health Sciences Centre, Toronto, ON, Canada. ${ }^{8}$ Canadian Centre for Applied Research in Cancer Control (ARCC), Toronto, ON, Canada. IInstitute of Health Policy, Management and Evaluation, University of Toronto, Toronto, ON, Canada. ${ }^{10} \mathrm{Centre}$ for Addiction and Mental Health, Toronto, ON, Canada. ${ }^{11}$ Gastroenterology Division, Massachusetts General Hospital, Boston, MA, USA. ${ }^{12}$ Harvard Medical School, Boston, MA, USA.

${ }^{13}$ Canadian Partnership Against Cancer, Toronto, ON, Canada.

Received: 8 February 2018 Accepted: 20 June 2018

Published online: 27 June 2018

\section{References}

1. Ferlay J, Soerjomataram I, Dikshit R, Eser S, Mathers C, Rebelo M, Parkin DM, Forman D, Bray F. Cancer incidence and mortality worldwide: sources, methods and major patterns in GLOBOCAN 2012. Int J Cancer. 2015;136(5): E359-86.

2. Hur C, Miller M, Kong CY, Dowling EC, Nattinger K, Dunn M, Feuer EJ. Trends in esophageal adenocarcinoma incidence and mortality. Cancer. 2013;119(6):1149-58.

3. Lepage C, Rachet B, Jooste V, Faivre J, Coleman MP. Continuing rapid increase in esophageal adenocarcinoma in England and Wales. Am J Gastroenterol. 2008;103(11):2694-9.

4. Pohl $\mathrm{H}$, Welch $\mathrm{HG}$. The role of overdiagnosis and reclassification in the marked increase of esophageal adenocarcinoma incidence. J Natl Cancer Inst. 2005:97(2):142-6.

5. El-Serag HB, Mason AC, Petersen N, Key CR. Epidemiological differences between adenocarcinoma of the oesophagus and adenocarcinoma of the gastric cardia in the USA. Gut. 2002;50(3):368-72.

6. Tinmouth J, Green J, Ko YJ, Liu Y, Paszat L, Sutradhar R, Rabeneck L. Urbach D. A population-based analysis of esophageal and gastric cardia adenocarcinomas in Ontario, Canada: incidence, risk factors, and regional variation. J Gastrointest Surg. 2011;15(5):782-90.
7. Rustgi AK, El-Serag HB. Esophageal carcinoma. N Engl J Med. 2014;371(26): 2499-509.

8. Zhang Y. Epidemiology of esophageal cancer. World J Gastroenterol. 2013; 19(34):5598-606.

9. Cancer Care Ontario. Cancer Fact: Changing patterns of esophageal cancer: adenocarcinoma on the rise. Sept. 2013. Available from: http://www. cancercare.on.ca/cancerfacts/. Accessed 3 May 2016.

10. Shaheen N, Ransohoff DF. Gastroesophageal reflux, Barrett esophagus, and esophageal cancer: scientific review. JAMA. 2002;287(15):1972-81.

11. Eisen GM, Sandler RS, Murray S, Gottfried M. The relationship between gastroesophageal reflux disease and its complications with Barrett's esophagus. Am J Gastroenterol. 1997;92(1):27-31.

12. Jansson C, Johansson AL, Nyren O, Lagergren J. Socioeconomic factors and risk of esophageal adenocarcinoma: a nationwide Swedish case-control study. Cancer Epidemiol Biomark Prev. 2005;14(7):1754-61.

13. Domper Arnal MJ, Ferrandez Arenas A, Lanas Arbeloa A. Esophageal cancer: risk factors, screening and endoscopic treatment in western and eastern countries. World J Gastroenterol. 2015;21(26):7933-43.

14. Cancer Care Ontario. Ontario Cancer Statistics 2018. Toronto: Cancer Care Ontario; 2018. Available from: https://www.cancercareontario.ca/sites/ ccocancercare/files/assets/OCS2018_2.pdf. Accessed 22 Apr 2018.

15. Bird-Lieberman EL, Fitzgerald RC. Early diagnosis of oesophageal cancer. Br J Cancer. 2009:101(1):1-6.

16. de Oliveira C, Bremner KE, Pataky R, Gunraj N, Chan K, Peacock S, Krahn MD. Understanding the costs of cancer care before and after diagnosis for the 21 most common cancers in Ontario: a population-based descriptive study. CMAJ Open. 2013;1(1):E1-8.

17. Enzinger PC, Mayer RJ. Esophageal cancer. N Engl J Med. 2003;349(23):224152.

18. de Oliveira C, Pataky R, Bremner KE, Rangrej J, Chan KK, Cheung WY, Hoch JS, Peacock S, Krahn MD. Phase-specific and lifetime costs of cancer care in Ontario. Canada BMC Cancer. 2016;16(1):809.

19. Inadomi JM. Surveillance in Barrett's esophagus: a failed premise. Keio J Med. 2009:58(1):12-8.

20. Hur C, Choi SE, Rubenstein JH, Kong CY, Nishioka NS, Provenzale DT, Inadomi JM. The cost effectiveness of radiofrequency ablation for Barrett's esophagus. Gastroenterology. 2012;143(3):567-75.

21. Brown ML, Riley GF, Potosky AL, Etzioni RD. Obtaining long-term disease specific costs of care: application to Medicare enrollees diagnosed with colorectal cancer. Med Care. 1999;37(12):1249-59.

22. Brown ML, Riley GF, Schussler N, Etzioni R. Estimating health care costs related to cancer treatment from SEER-Medicare data. Med Care. 2002;40(8 Suppl):IV-104-17.

23. Baker MS, Kessler LG, Urban N, Smucker RC. Estimating the treatment costs of breast and lung cancer. Med Care. 1991;29(1):40-9.

24. Taplin SH, Barlow W, Urban N, Mandelson MT, Timlin DJ, Ichikawa L, Nefcy P. Stage, age, comorbidity, and direct costs of colon, prostate, and breast cancer care. J Natl Cancer Inst. 1995;87(6):417-26.

25. Yabroff KR, Lamont EB, Mariotto A, Warren JL, Topor M, Meekins A, Brown ML. Cost of care for elderly cancer patients in the United States. J Natl Cancer Inst. 2008;100(9):630-41.

26. Clarke EA, Marrett LD, Kreiger N. Cancer registration in Ontario: a computer approach. IARC Sci Publ. 1991;95:246-57.

27. Robles SC, Marrett LD, Clarke EA, Risch HA. An application of capturerecapture methods to the estimation of completeness of cancer registration. J Clin Epidemiol. 1988;41(5):495-501.

28. Holowaty E. The Ontario Cancer registry : a registry with almost completely automated data collection. In: Black RJ, Simonato L, Storm HH, Démaret E, editors. Automated data collection in Cancer registry. IARC technical reports. No. 32, Lyon, France, IARC press; 1998. p. 39-44.

29. Holowaty EJ, Moravan V, Lee G, Chong N, Dale D. A reabstraction study to estimate the completeness and accuracy of data elements in the Ontario Cancer Registry. A Report to Health Canada. Toronto: Ontario Cancer Registry; 1996.

30. Holowaty E. The Ontario Cancer registry : summarization of information from multiple data sources. In: Black RJ, Simonato L, Storm HH, Démaret E, editors. Automated data collection in Cancer registry. IARC technical reports. No. 32, Lyon, France, IARC press; 1998. p. 39-44.

31. ClHI's Data Source Assessment Tool. ( 2017 Canadian institute for health information. Available from: : https://secure.cihi.ca/free_products/CIHI-datasource-assessment-tool-en.pdf. Accessed 20 Apr 2018. 
32. Wodchis WP, Bushmeneva K, Nikitovic M, McKillop I. Guidelines on personlevel costing using administrative databases in Ontario. Working paper series. Vol 1. Toronto: health system performance research. Network. 2013;

33. Jacobs P, Yim R. Using Canadian administrative databases to derive economic data for health technology assessments. Ottawa: Canadian Agency for Drugs and Technologies. in Health. 2009. Available from: https://www.cadth.ca/media/pdf/H0483_Canadian_Admin_Databases_mg_ e.pdf; Accessed 19 Jan 2017

34. You JJ, Wong RK, Darling G, Gulenchyn K, Urbain JL, Evans WK. Clinical utility of 18F-fluorodeoxyglucose positron emission tomography/computed tomography in the staging of patients with potentially resectable esophageal cancer. J Thorac Oncol. 2013;8(12):1563-9.

35. Thein HH, Isaranuwatchai W, Campitelli MA, Feld JJ, Yoshida E, Sherman M Hoch JS, Peacock S, Krahn MD, Earle CC. Health care costs associated with hepatocellular carcinoma: a population-based study. Hepatology. 2013;58(4): 1375-84.

36. Fleming IDAJCC. TNM cancer staging. present and future J Surg Oncol. 2001;77(4):233-6.

37. Ontario Local Health Integration Network Available from: http://www.Ihins on.ca/. Accessed 1 Nov 2016.

38. Starfield B, Weiner J, Mumford L, Steinwachs D. Ambulatory care groups: a categorization of diagnoses for research and management. Health Serv Res. 1991;26(1):53-74.

39. Weiner JP, Starfield BH, Steinwachs DM, Mumford LM. Development and application of a population-oriented measure of ambulatory care case-mix. Med Care. 1991;29(5):452-72.

40. Reid RJ, MacWilliam L, Verhulst L, Roos N, Atkinson M. Performance of the ACG case-mix system in two Canadian provinces. Med Care. 2001;39(1):8699.

41. Reid RJ, Roos NP, MacWilliam L, Frohlich N, Black C. Assessing population health care need using a claims-based ACG morbidity measure: a validation analysis in the province of Manitoba. Health Serv Res. 2002;37(5):1345-64.

42. The Johns Hopkins ACG ${ }^{\oplus}$ System Excerpt from Version 11.0 Technical Reference Guide. The Johns Hopkins University, 2015. Available from: http://www2.gov.bc.ca/assets/gov/health/conducting-health-research/dataaccess/johns-hopkins-acg-system-technical-reference-guide.pdf. Accessed 16 Aug 2017.

43. The Johns Hopkins ACG ${ }^{\circledast}$ System. Decades of Impact on Population Health Research and Practice Available from: https://www.hopkinsacg.org/. Accessed 16 Aug 2017.

44. Austin PC, van Walraven C, Wodchis WP, Newman A, Anderson GM. Using the Johns Hopkins aggregated diagnosis groups (ADGs) to predict mortality in a general adult population cohort in Ontario. Canada Med Care. 2011; 49(10):932-9.

45. Brown LM, Devesa SS, Chow WH. Incidence of adenocarcinoma of the esophagus among white Americans by sex, stage, and age. J Natl Cancer Inst. 2008;100(16):1184-7.

46. Rosenbaum PR, Rubin DB. Reducing bias in observational studies using subclassification on the propensity score. J Am Stat Assoc. 1984;79(387): 516-24

47. Rosenbaum PR, Rubin DB. Constructing a control group using multivariate matched sampling methods that incorporate the propensity score. Am Stat. 1985;39(1):33-8.

48. Austin PC. Optimal caliper widths for propensity-score matching when estimating differences in means and differences in proportions in observational studies. Pharm Stat. 2011;10(2):150-61.

49. Baladi JF. A guidance document for the costing process, version 1.0. Ottawa: Canadian Coordinating Office for Health Technology Assessment; 1996.

50. Pink GH, Bolley HB. Physicians in health care management: 3. Case mix groups and resource intensity weights: an overview for physicians. CMAJ. 1994;150(6):889-94.

51. Pink GH, Bolley HB. Physicians in health care management: 4. Case mix groups and resource intensity weights: physicians and hospital funding. CMAJ. 1994;150(8):1255-61.

52. Consumer Price Index, health and personal care, by province (Ontario) Available from: http://www.statcan.gc.ca/tables-tableaux/sum-som/l01/ cst01/econ161g-eng.htm. Accessed 17 Aug 2017.

53. Kleine-Budde K, Muller R, Kawohl W, Bramesfeld A, Moock J, Rossler W. The cost of depression - a cost analysis from a large database. J Affect Disord. 2013;147(1-3):137-43.
54. Briggs A, Nixon R, Dixon S, Thompson S. Parametric modelling of cost data: some simulation evidence. Health Econ. 2005:14(4):421-8.

55. Manning WG, Mullahy J. Estimating log models: to transform or not to transform? J Health Econ. 2001;20(4):461-94.

56. Maldonado G, Greenland S. Simulation study of confounder-selection strategies. Am J Epidemiol. 1993;138(11):923-36.

57. Budtz-Jorgensen E, Keiding N, Grandjean P, Weihe P. Confounder selection in environmental epidemiology: assessment of health effects of prenatal mercury exposure. Ann Epidemiol. 2007;17(1):27-35.

58. Walter SR, Thein HH, Gidding HF, Amin J, Law MG, George J, Dore GJ. Risk factors for hepatocellular carcinoma in a cohort infected with hepatitis B or C. J Gastroenterol Hepatol. 2011;26(12):1757-64.

59. Goense L, van Dijk WA, Govaert JA, van Rossum PS, Ruurda JP, van Hillegersberg R. Hospital costs of complications after esophagectomy for cancer. Eur J Surg Oncol. 2017;43(4):696-702.

60. Dimick JB, Pronovost PJ, Cowan JA, Lipsett PA. Complications and costs after high-risk surgery: where should we focus quality improvement initiatives? J Am Coll Surg. 2003;196(5):671-8.

61. van Hagen $P$, Hulshof MC, van Lanschot JJ, Steyerberg EW, van Berge Henegouwen MI, Wijnhoven BP, Richel DJ, Nieuwenhuijzen GA, Hospers GA Bonenkamp JJ, et al. Preoperative chemoradiotherapy for esophageal or junctional cancer. N Engl J Med. 2012;366(22):2074-84.

62. Vaughan TL, Fitzgerald RC. Precision prevention of oesophageal adenocarcinoma. Nat Rev Gastroenterol Hepatol. 2015;12(4):243-8.

63. Bhat SK, McManus DT, Coleman HG, Johnston BT, Cardwell CR, McMenamin U, Bannon F, Hicks B, Kennedy G, Gavin AT, et al. Oesophageal adenocarcinoma and prior diagnosis of Barrett's oesophagus: a populationbased study. Gut. 2015;64(1):20-5.

64. Tramontano AC, Sheehan DF, Yeh JM, Kong CY, Dowling EC, Rubenstein JH, Abrams JA, Inadomi JM, Schrag D, Hur C. The impact of a prior diagnosis of Barrett's esophagus on esophageal adenocarcinoma survival. Am J Gastroenterol. 2017;112(8):1256-64.

\section{Ready to submit your research? Choose BMC and benefit from:}

- fast, convenient online submission

- thorough peer review by experienced researchers in your field

- rapid publication on acceptance

- support for research data, including large and complex data types

- gold Open Access which fosters wider collaboration and increased citations

- maximum visibility for your research: over $100 \mathrm{M}$ website views per year

At BMC, research is always in progress.

Learn more biomedcentral.com/submissions 